\title{
Knowledge Creation and Regional Spillovers: Empirical Evidence from Germany
}

\begin{abstract}
The paper examines the effects of intra- and inter-regional knowledge spillovers on innovative activities in German states using the augmented Griliches-Jaffe knowledge production function. The "Harris market potential" type index is calculated to proxy for inter-regional knowledge transfers of two types: industrial knowledge transfers generated from the business enterprise sector and academic spillovers generated from universities across all German states. The model also includes the concentration of high-tech enterprises, in order to capture the agglomeration effect in the local economy. The estimation results reveal that not only do local private and university research efforts have a positive and significant effect on local innovative activities, but there are also important interregional knowledge spillovers across the German regions.
\end{abstract}

\section{Keywords}

Augmented Griliches-Jaffe knowledge production function • innovation • knowledge spillovers • regions • Germany

(c) University of Warsaw - Faculty of Geography and Regional Studies
Tinatin Akhvlediani', Andrzej Cieślik ${ }^{2}$

'Department of Economics, College of Europe Belgium

e-mail: tinatin.akhvlediani@coleurope.eu

${ }^{2}$ Faculty of Economic Sciences,

University of Warsaw , Poland

e-mail: cieslik@wne.uw.edu.pl

Received: 20 January 2017

Accepted: 15 November 2017
Introduction

One of the greatest contributions in the literature on the economics of innovation and technological progress in the last decade has been the insight that geography matters. While investigating the main reasons why high-tech enterprises might be concentrated in certain spaces, the empirical research shows that, together with agglomeration effects, knowledge spillovers also play an important role. Individual or business interactions diffuse knowledge, resulting in positive externalities spreading spatially. However, elaborating further on the sources of knowledge spillovers, recent empirical studies show that, together with the research and development efforts (R\&D) of the business enterprise sector, universities can also contribute to knowledge spillovers.

The first formal indication of positive effects of university research on company performance was provided by Nelson (1986). To empirically account for the effect of geographic knowledge spillovers on regional innovative capacity, the Griliches-Jaffe knowledge production function (KPF) offers implicit measure (Griliches 1979; Jaffe 1989). This function is in fact a generalised two-factor Cobb-Douglas production function which relates new knowledge produced by high-tech firms to industrial R\&D and university research activities. Thus, that production of new knowledge depends on two local inputs: the high-tech industry's own R\&D and local university research. Typically, new knowledge is measured by the number of patents, while industrial R\&D and university research are measured in terms of employment or expenditures. As underlined by Jaffe (1989), the positive and significant effect of university research on new knowledge indicates the existence of knowledge spillovers from local universities in regional innovative activities. The higher the value of the estimated coefficient on this variable, the more intensive the effect of academic knowledge spillovers on local innovations. By contrast, if the coefficient of university research were insignificant, it would suggest that all innovative knowledge is generated through industrial sector research efforts.

Empirical research based on the Griliches-Jaffe knowledge production function was initially focused on a US case. For instance, Varga (2000) used this framework to analyze the agglomeration effects and knowledge transfers from local universities on hightech innovations in metropolitan statistical areas (MSA) in the US. Specifically, he modified the knowledge production function by constructing a hierarchical system of coefficients to model economically useful new technological knowledge as dependent on the interaction of industrial and university R\&D with local agglomeration factors (those factors being the concentrations of high-tech production, business services and large companies). Ordinary Least Square (OLS) and IV-Spatial Lag estimations for regressions on $125 \mathrm{MSAs}$ in 1982 revealed that the same amount of university research spending might be associated with drastically different rates of innovations, depending on the concentration of economic activities in metropolitan areas. Later, research also covered European countries. For instance, Fischer and Varga (2003) used more explicit measure of the pool of spatial academic knowledge spillovers on the regional knowledge production in high-tech industries in Austria in 1993. Their study revealed that geographically mediated knowledge spillovers from university research activities have positive effects on regional knowledge production in high-tech industries. 
This paper makes use of KPF and extends the literature on the European countries, and specifically on Germany. In particular, the main goal of the paper is to study the role of regional knowledge spillovers in innovative activities across German states in 1991-2009. We selected Germany since this country exhibits not only high-tech firm concentration but also university concentration. For instance, compared to the US, universities in Germany are geographically more concentrated. Moreover, along with intra-regional spillovers, we also test for the effects of two sources of inter-regional spillovers: industrial knowledge transfers generated from the business enterprise sector and academic spillovers generated from universities across all German states. Thus we highlight the role of positive externalities and show that industrial and university R\&D in one German region may contribute not only in the innovation activities of this particular region, but also in knowledge creation in the neighbouring regions. The main added value of the paper is the application of the "Harris (1954) market potential" type of index to design variables for the aforementioned knowledge transfers across regions. The empirical model is also augmented with the concentration of high-tech enterprises in order to capture the agglomeration effects.

The remainder of this paper is structured as follows. In the next section we provide the relevant literature review. Then we describe the research methodology and the data. Subsequently, we discuss our estimation results. Finally, in the last section, we summarise and draw conclusions.

\section{Literature review}

The view that knowledge may spill over from universities to firms has been supported by a number of empirical studies. The most frequently cited examples include, inter alia, Jaffe (1989), Jaffe et al. (1993), Acs et al. (1994), and Audretsch and Feldman (1996). Moreover, as outlined in the recent empirical studies, we should also take into account the agglomeration effects reinforcing the impacts of regional knowledge spillovers. The literature highlights that we may distinguish three different kinds of agglomeration effects: concentration of high-tech production, which is assumed to intensify information flows through industry and university personal networks (Anselin et al. 1997; Audretsch et al. 2012; Varga 2000); business service firm concentration, which enlarges knowledge transfers by facilitating faculty spin-offs or technology licensing through the provision of financial, legal, and marketing assistance; and the existence of small-firm concentrations, since they are less well endowed with research facilities than large firms and therefore exhibit more reliance on university knowledge spillovers (Link and Rees 1990; Acs et al. 1994). Thus, to include agglomeration effects on local knowledge spillovers, the knowledge production function might be augmented by local characteristics relating to the concentrations of high-tech production, business services and small firms.

However, in addition to the existence of knowledge spillovers, the literature also indicates that the impacts of knowledge spillovers are geographically bounded. For example, Gaspar and Glaeser (1996) demonstrate that while the cost of transmitting information across regions and countries is actually invariant to distance, due to the internet revolution, the marginal costs of transmitting tacit knowledge rise with distance because noncodified knowledge is vague and requires face-to-face interaction. As a result, R\&D spillovers may be spatially restricted and, thus, studies of the spatial extent of positive externalities take on vital importance.

Anselin et al. (1997) examine the spatial extent of the impacts of university research on high-tech innovations in the US. Their study is based on the estimating equation derived from the GrilichesJaffe knowledge production function. A count of innovations that were introduced onto the US market in 1982 is used as the dependent variable. As for the independent variables, the authors include private $R \& D$ expenditures and university research expenditures. They also control for the agglomeration effects by including high-tech employment, and employment in business services and firms employing over 500 employees. Additionally, to control for the distance effect, two spatial-lag variables are added into the model. OLS estimation results confirm the positive and significant relationship between university research and innovative activity. However, the authors find that spillovers of university research on innovation extend over a range of 50 miles from the innovating MSA.

Funke and Niebuhr (2000) distinguish between the effects of regions' own R\&D efforts and inter-regional industry spillovers on the regional productivity of the West German functional regions in 1976-1977. The authors use the number of R\&D employees to approximate the potential of the respective region. The negative relation between distance and intensity of spatial interaction of R\&D employees is taken into account. Namely, the R\&D potential measure consists of the self-potential of region $i$ and the cumulated influence of the other $(R-1)$ regions, which declines with increasing distance between the centres of the regions $i$ and $j$ according to the negative exponential function. The cross sectional data is analyzed by least trimmed squares (LTS) estimation. The regression reveals a positive coefficient for R\&D potential with a high distance decay parameter. More precisely, the intensity of spillovers declines by $50 \%$ over a range of 30 kilometres. Finally, the authors find that on average the spatial effects decrease by $60 \%$ between the centres of two neighbouring regions.

Furthermore, Anselin et al. (2000) conducted sectoral analyses of innovations at the MSA levels in the United States in 1982. They show that together with regional differences there also exist sectoral differences in the innovative process. Their paper, similar to the other aforementioned studies, also uses the estimation equation based on the framework of the GrilichesJaffe knowledge production function to model knowledge creation as a function of industrial and university research together with agglomeration effects (i.e. high-tech employment, employment in business services and the presence of large firms to control the effects of scale). OLS and IV-Spatial Lag regressions show no uniform evidence of positive externalities for university research, depending on either the regional or sectoral differences in innovation activities.

As for studies concerning the German case, Fritsch and Franke (2004) also use the knowledge production function to investigate the impact of knowledge spillovers and R\&D expenditures on innovation activities in three German regions. The main data source of their analysis is information gathered from postal questionnaires sent to manufacturing enterprises in three German regions. Besides the innovative activities of manufacturing enterprises, the information collected covers the number of cooperative relationship with other private sector firms and public research institutions. The authors estimate two models. First, they use the logit regression for the model where the dependent variable indicates whether or not an enterprise had registered an innovation for patenting in the preceding three years. The second model is estimated by the negative binomial regression since in this case the dependent variable is the number of innovations registered for patenting. Finally, the authors explain inter-regional differences in innovative activities based on the spillovers, which in fact are presented as the R\&D expenditures of other private firms and public research institutions located in the same region.

Audretsch et al. (2005) study the impact of university output on business-location decisions made by new firms in Germany. The authors use a unique dataset of all the German high-tech and 
knowledge firms publicly listed on the "Neuer Mark" for 19972002. The distance of a new knowledge-based firm to the closest university is used as the endogenous variable. The independent variables are categorised into three main groups. The first group contains spillover mechanism variables for research and human capital. That is, to capture the spillover mechanism for research, the number of articles published in high quality journals is included. Human capital spillovers are proxied by the number of students enrolled at each university. The second group of exogenous variables consists of location variables, which contain university and firm location variables. And finally, the third group considers firm-specific variables. Estimation results of their OLS regressions reveal that new firms in high-tech industries are influenced not only by the traditional regional characteristics, but also by the opportunity to access knowledge generated by universities.

More recently, Audretsch et al. (2012) examine how regional competitiveness and university spillovers affect the innovation behaviour of entrepreneurial firms in Germany. The authors express the number of firm patents as a function of regional competitiveness, the existence of a university output, and industryand firm-specific variables. Since their dependent variable is discrete rather than continuous, they use the negative binomial regression and estimate four models: the first model includes only industry variables and firm size to explain the number of patents; the second model expands the first specification by including variables measuring regional competitiveness; the third model employs the university variables; and, finally, the fourth model estimates the effects of all variables jointly. Their estimation results suggest that while regional competitiveness is the strong determinant of the innovation behaviour of young and small firms it significantly shapes the innovation behaviour only if research intensive universities are located in the region.

When discussing the role of distance, we may also consider the paper by Castellani et al. (2013) highlighting that the distance can have higher or lower impact on R\&D spillovers depending on the activity of a given firm. Specifically, the authors employ data on the R\&D and manufacturing investment decisions of 6,320 firms in 59 countries and find that, when institutional proximity factors are accounted for, geographic distance does not help to explain the location of R\&D investments. The paper also shows that geographic proximity matters more for manufacturing activities than for R\&D activities. The intuition is that big firms develop their own networks, which enables knowledge to spill over throughout their entire own network of big enterprises even if they have branches overseas. Additionally, according to their estimations, the main obstacle for knowledge spillovers could be other barriers stemming from institutional differences, including cultural ties and language barriers. Given these findings, if we analyze firms in the same country, in this case in Germany, institutional proximity should not be so binding and geographical distance may have larger effects for knowledge spillovers across regions.

As the above review of the literature shows, the topic is mainly analyzed using the Griliches-Jaffe knowledge production function. In addition to the standard variables of the model, empirical studies control also for agglomeration and firm-scale effects. The findings of the literature show that university research expenditures exert a positive and significant impact on local innovative activities, indicating the existence of local university spillovers. Previous studies conducted for the US also show that positive externalities are diffused from neighbouring regions and that their impacts decline with distance. However, studies of the spatial extent of knowledge spillovers for Germany are still relatively scarce. Therefore, together with evaluating the effects of intra-regional university spillovers on the regional innovative activities, our study aims to elaborate on the existence of inter- regional industrial and academic knowledge transfers across German states. Our variables standing for the inter-regional knowledge spillovers are patterned on the market potential index proposed by Harris (1954).

Overall, the paper attempts to test the following three research hypothesis: i) research activities of local universities increase local innovative activities; ii) industrial knowledge spillovers across German states increase regional innovative activities; iii) university spillovers across German states increase regional innovative activities.

\section{Research methodology and data description}

Based on the literature review provided in the previous section, to study the effects of knowledge spillovers on the regional innovation activities we employ the following augmented knowledge production function:

$$
\begin{gathered}
\log (K)_{i t}=\alpha+\beta \log (R D)_{i t}+\gamma \log (U R D)_{i t}+\delta \log (E m p l)_{i t}+\theta \log (I s p)_{i t} \\
+\phi \log (U s p)_{i t}+\mathrm{c}_{i}+\varepsilon_{i t}
\end{gathered}
$$

where:

- $\quad \log (K)_{\text {it }}$ denotes the number of patents in application in region $i$ at time $t$ used as our measure of knowledge creation; $\log (R D)_{i t}$ stands for the expenditures on research and development of the business enterprise sector in region $i$ at time $t$;

$\log (U R D)_{i t}$ is the expenditures on research and development of the higher education sector in region $i$ at time $t$;

$\log (E m p l)_{\text {it }}$ presents employment in technology and knowledge intensive sectors in region $i$ at time $t$;

- $\quad \log (I s p)_{i t}$ denotes knowledge transfers from the business enterprise sector in region $i$ from all other $(n-1)$ regions at time $t$

- $\log (U s p)_{i t}$ denotes knowledge transfers from the higher education sector in region $i$ from all other $(n-1)$ regions at time $t$;

$c_{i}$ is the individual effect specific to the region;

- $\quad \varepsilon_{i t}$ is the error term, which is assumed to be normally distributed with mean zero.

Even though we use a log-log specification, this may not solve the possibility of unobserved heterogeneity and the possibility of correlated error terms. Therefore, in order to address this issue in the empirical model we include the time invariant individual effect $c_{i}$ for each German state. Hence, the joint error term can be provided as $v_{i t}=c_{i}+\varepsilon_{i t}$ In the case when the individual effect $c_{i}$ is correlated with the explanatory variables, the estimation with OLS may suffer from simultaneity bias due to the correlation between the joint error term and explanatory variables. In this case, fixed effects (FE) estimation would be an adequate methodology. However, when the assumption of the strict exogeneity and no correlation between independent variables and the individual effect is satisfied, random effect (RE) estimation would be the proper econometric technique to follow. To identify the proper estimation format for each model, we use the Hausman test which favours fixed effect estimation for the benchmark model and random effect estimation for the rest of the models. ${ }^{1}$ Thus our analysis takes into account unobserved heterogeneities across German states. In other words, by employing FE and RE we eliminate biased estimations by correlating the region-specific individual effects and the error term.

- $\quad$ The variables denoting the inter-regional knowledge transfers from the business enterprise and higher education sectors are patterned on the market potential index proposed by Harris

'Hausman's test favoured fixed effects for the benchmark estimations and random effects for the rest of the specifications, see last two rows of Table 2. 
(1954). The concept of the Harris index implied that the market potential of a site was defined based on its access to markets to which it might sell. This involved the purchasing power of all markets and the distance to those markets. In a similar way, knowledge transfers from the business enterprise and the higher education sectors are calculated as follows:

$$
\begin{aligned}
& I s p=\sum_{i \neq j}^{n} \frac{R D_{i}}{D_{i j}} \\
& U s p=\sum_{i \neq j}^{n} \frac{U R D_{i}}{D_{i j}}
\end{aligned}
$$

In other words, these two variables present the summation of regional $R \& D$ expenditures by business enterprises and by universities, respectively, each weighted by the distance between regions.

The data for all the variables are taken from the Eurostat regional database by NUTS 2 classification covering 16 German states for 9 periods in 1991-2009. ${ }^{2}$ According to the data availability the model contains data for the following years: 1991 , 1993, 1995, 1997, 1999, 2003, 2005, 2007, 2009. The number of patents in application is the proxy for the output of knowledge; R\&D expenditures by the business enterprise sector denote industrial research activities; in the same way research expenditures by the higher education sector measure university research activities. Employment in technology- and knowledge-intensive sectors is the proxy for the concentration of high-tech enterprises across regions which shows the agglomeration effect of knowledge spillovers on regional innovative activities. ${ }^{3}$ For some robustness checks we also include variables on population in the model. Namely, we control for population density in every region and for the relative size of the region measured by the ratio of its population to the entire population in Germany. While the former stands for the agglomeration effects, the later approximates the variability of the region's size over time. The distance between the regions is the driving distance between the capitals of the German states calculated by the google.map calculator. The summary statistics for our dependent and explanatory variables are provided in Table 1.

\section{Estimation results}

To test the three research hypotheses we estimated three models. The first model is the benchmark model to test whether research expenditures by local universities increase local innovation activities. It contains only variables measuring industrial R\&D, university research efforts and concentration of high-tech firms. The second model is augmented with the variable denoting industrial knowledge transfers across regions, to test for the effect of industrial knowledge spillovers on local knowledge creation. Finally, the third model contains university spillovers, to test for the effect of knowledge transfers from universities across German states on local knowledge creation. However, we should note that, because of the collinearity of variables standing for industrial knowledge transfers and university knowledge transfers, we could not include both variables in the model at the same time, since it would not generate consistent results. ${ }^{4}$ Our estimation results of all three models are reported in the respective columns of Table 2 .

\footnotetext{
${ }^{2}$ See the list of the German states provided in the appendix.

${ }^{3}$ The other two channels of agglomeration effects, namely, presence of large firms and concentration of business services in the local economy, are not included in the model since the Eurostat regional database does not contain this data.

${ }^{4}$ Correlation between these variables is 0.9572
}

Table 1. Summary Statistics

\begin{tabular}{|c|c|c|c|c|c|}
\hline Variable & Obs & Mean & $\begin{array}{c}\text { Std. } \\
\text { Dev. }\end{array}$ & Min & Max \\
\hline Ipatents & 144 & 5.98 & 1.61 & 2.08 & 8.74 \\
\hline IRD & 144 & 6.63 & 1.56 & 3.50 & 9.47 \\
\hline IURD & 144 & 5.84 & 0.92 & 4.00 & 7.84 \\
\hline IUsp & 144 & 3.22 & 0.42 & 2.49 & 4.63 \\
\hline IIsp & 144 & 4.55 & 0.50 & 3.85 & 6.32 \\
\hline IempI & 144 & 4.16 & 1.02 & 2.28 & 6.02 \\
\hline Ipop_dens & 96 & 5.74 & 1.12 & 4.27 & 8.26 \\
\hline IPOP & 144 & 0.83 & 0.05 & 0.74 & 0.92 \\
\hline
\end{tabular}

Source: own computations performed in STATA 15.

The estimation results obtained for the benchmark model are reported in column (1). This model tests whether research expenditures by local universities increase local innovation activities. It contains only variables measuring industrial R\&D, university research efforts and concentration of high-tech firms. Our estimation results obtained via the fixed effect method show that the coefficient on the variable measuring the research expenditures of universities is positive and significant already at the $1 \%$ significance level. The estimated coefficients on two other variables, namely local industrial R\&D and concentration of high-tech firms, are also found to be positive and statistically significant at the $1 \%$ and $5 \%$ significance levels, respectively. The positive and statistically significant coefficient on concentration of high-tech firms emphasises the existence of the agglomeration effect which reinforces the effects of the local R\&D expenditures of local business enterprises and local universities. Moreover, of these three explanatory variables, the estimated coefficient on the research expenditures of local universities is the highest, indicating the strong effect of university research efforts on the number of patents in German states. Therefore, the first research hypothesis stating that research activities of local universities are positively related to local innovative activities cannot be rejected.

The second model extends the benchmark model specification with the variable measuring industrial knowledge transfers across regions. The results of the random effect estimation reveal that the estimated coefficient on this variable is positive and significant already at the $1 \%$ level. It is also worth noting that all three variables of the benchmark model remain statistically significant although the values of the estimated coefficients on both local industry and university research expenditures are lower than the results reported in column (1). In particular, the coefficient on the university research expenditures is now halved. Therefore, it may be concluded that ignoring industrial knowledge spillovers across regions might overestimate the effects of local university research efforts on local innovative activities. Hence, the second research hypothesis stating that industrial knowledge spillovers across German states are positively related to the number of patents in regions cannot be rejected.

The third specification of the model tests the effect of knowledge transfers from universities on the effects of local innovation activities. The estimation results of the random effects model reveal that the variable measuring knowledge transfers from universities across German states displays a positive and statistically significant coefficient at the $1 \%$ level. This implies that knowledge spillovers from universities across regions exist and 
MISCELLANEA GEOGRAPHICA - REGIONAL STUDIES ON DEVELOPMENT

Vol. $21 \cdot$ No. $4 \cdot 2017 \cdot$ pp. 184-189 •ISSN: 2084-6118 • DOI: 10.1515/mgrsd-2017-0033

Table 2. Estimation Results

\begin{tabular}{|c|c|c|c|c|c|c|c|}
\hline & (1) & (2) & (3) & (4) & (5) & (6) & (7) \\
\hline \multirow[t]{2}{*}{ IRD } & $0.549^{\star \star \star}$ & $0.369^{* * *}$ & $0.383^{* * *}$ & $0.216^{\star \star \star}$ & $0.225^{\star \star *}$ & $0.380^{\star \star *}$ & $0.433^{* * \star}$ \\
\hline & $(0.115)$ & $(0.0883)$ & $(0.0965)$ & $(0.0809)$ & $(0.0827)$ & $(0.0919)$ & $(0.100)$ \\
\hline \multirow[t]{2}{*}{ IURD } & $1.083^{\star \star \star}$ & $0.549^{* \star *}$ & $0.629^{\star \star \star}$ & 0.156 & 0.187 & $0.563^{\star \star \star}$ & $0.771^{\star \star \star}$ \\
\hline & $(0.186)$ & $(0.155)$ & $(0.169)$ & $(0.136)$ & $(0.142)$ & $(0.166)$ & $(0.179)$ \\
\hline \multirow[t]{2}{*}{ lempl } & $0.391^{* *}$ & $0.392^{* *}$ & $0.417^{* *}$ & $0.781^{\star \star \star}$ & $0.804^{\star * \star}$ & $0.364^{\star *}$ & $0.522^{\star \star \star}$ \\
\hline & $(0.202)$ & $(0.157)$ & $(0.172)$ & $(0.136)$ & $(0.140)$ & $(0.176)$ & $(0.193)$ \\
\hline \multirow[t]{2}{*}{ Ilsp } & & $0.841^{* \star *}$ & & $0.219^{\star \star}$ & & $0.859^{\star \star \star}$ & \\
\hline & & $(0.113)$ & & $(0.109)$ & & $(0.154)$ & \\
\hline \multirow[t]{2}{*}{ IUsp } & & & $0.654^{\star \star \star}$ & & 0.0288 & & $0.410^{\star *}$ \\
\hline & & & $(0.141)$ & & $(0.113)$ & & $(0.198)$ \\
\hline \multirow[t]{2}{*}{ Ipop_dens } & & & & -0.00857 & -0.0259 & & \\
\hline & & & & $(0.0812)$ & $(0.0792)$ & & \\
\hline \multirow[t]{2}{*}{ Ipop } & & & & & & -0.0436 & -0.478 \\
\hline & & & & & & $(0.225)$ & $(0.251)$ \\
\hline \multirow[t]{2}{*}{ constant } & $-5.61^{\star \star \star}$ & $-5.14^{\star * \star}$ & $-4.08^{\star \star \star}$ & -0.404 & 0.286 & $-5.39^{* * *}$ & $-6.39^{\star \star \star}$ \\
\hline & $(0.844)$ & (0.588) & $(0.614)$ & $(0.706)$ & $(0.634)$ & (1.152) & $(1.306)$ \\
\hline $\begin{array}{c}\text { Region-specific } \\
\text { effect }\end{array}$ & Fixed & Random & Random & Random & Random & Random & Random \\
\hline R-sq within & 0.612 & 0.690 & 0.615 & 0.5257 & 0.4875 & 0.6924 & 0.6342 \\
\hline R-sq between & 0.907 & 0.936 & 0.934 & 0.9646 & 0.9522 & 0.9315 & 0.9164 \\
\hline R-sq overall & 0.872 & 0.912 & 0.903 & 0.9534 & 0.9416 & 0.9084 & 0.8892 \\
\hline $\mathrm{N}$ of groups & 16 & 16 & 16 & 16 & 16 & 16 & 16 \\
\hline $\mathrm{N}$ of obs & 144 & 144 & 144 & 96 & 96 & 144 & 144 \\
\hline chi2 & 58.10 & 5.16 & 7.42 & 9.49 & 10.11 & 8.75 & 18.8 \\
\hline Prob>chi2 & 0.000 & 0.271 & 0.115 & 0.101 & 0.098 & 0.109 & 0.07 \\
\hline
\end{tabular}

Note: The explained variable in all specifications is the natural logarithm of the number of patents in every region of Germany. Due to limited data availability, estimations cover 1991-2009.

Standard errors in parentheses; * - denotes $p<0.1,{ }^{* *}$ - denotes $p<0.05,{ }^{* * *}$ - denotes $p<0.01$.

Source: own estimations performed in STATA 15.

increase the number of patents in German states. However, it should be noted that the magnitude of the estimated coefficient on the university knowledge spillovers is lower than that of the coefficient on industrial knowledge transfers. This finding is in line with previous findings reported in the literature for other countries. In particular, Fischer and Varga (2003), who studied the spatial extent of R\&D efforts in Austria, found that the effect of university research was much smaller than the industry R\&D effect.

In addition, none of the remaining three other variables lost either their signs or their statistical significance. However, as in the case of the second model, the values of the estimated coefficients on local industry and university research expenditures were both greatly reduced. Therefore, we may again state that not controlling for positive externalities from industrial and higher education sectors might overestimate the effects of research efforts of local firms and universities on innovative activities in German regions. Summing up, the third research hypothesis stating that university spillovers across German states increase regional innovative activities cannot be rejected.

Finally we provide some sensitivity checks to the benchmark estimations. As discussed in the previous section, we control for population density in every region and for the relative size of the region measured by the ratio of its population to the entire population in Germany. As columns (4)-(5) report, the coefficient of the variable standing for population density does not yield statistically significant impact. Instead, once population density is included in the model, the variable standing for spillovers from universities loses statistical significance. This can be explained by the limited number of observations since, by including population density in the model, we lose observations. Columns (6)-(7) extend the model with additional variables standing for the relative size of regions. In this case, we do not lose the number of observations and, as the estimations indicate, neither the magnitude nor the signs of the coefficients change significantly. Indeed, results are quite similar to the benchmark estimations. The new variable is not itself statistically significant. Therefore, we may conclude on the one hand that adding additional controls for population does not explain the model better while, on the other, once the number of observations does not drop, our estimations remain robust to sensitivity checks.

\section{Conclusions}

The paper aimed to study the role of knowledge spillovers in innovative activities across German states over the period 19912009. Together with intra-regional spillovers, the paper tested the effects of two potential sources of inter-regional spillovers: industrial knowledge transfers generated from the business enterprise sector and academic spillovers generated from universities across all German states. The variables measuring the extent of knowledge transfers were patterned on the market potential index proposed by Harris (1954). The empirical study 
was based on the KPF offered by Griliches and Jaffe (Griliches 1979; Jaffe 1989). Along with additional variables measuring interregional knowledge spillovers, the model was augmented with the concentration of the high-tech enterprises to capture the agglomeration effect.

The estimation results for the benchmark model obtained via the fixed effect estimation method showed that research expenditures of local universities were positively related to the number of patents in the region. Therefore, the research hypothesis concerning the existence of local university spillovers could not be rejected. The concentration of high-tech enterprises was also found to have positive and significant impacts, underlining the agglomeration effect on regional innovative activities. Estimations of the second and the third models obtained via the random effect estimation method revealed positive and significant coefficients on variables measuring inter-regional knowledge spillovers of those originating from university research and those from industrial R\&D. Thus, in addition to local university spillovers, the existence of knowledge transfers across regions was also confirmed. Moreover, the estimation results showed that, when controlling for inter-regional knowledge transfers, the effect of local university spillovers is greatly reduced.

Additionally, we provided some sensitivity checks for the benchmark estimations. That is, we controlled for population density in every region and for the relative size of the region measured by the ratio of its population to the entire population in Germany. As estimations indicated, on the one hand, adding additional controls for population does not explain the model better, while, on the other, when the number of observations does not drop, our estimations remained robust to the sensitivity checks.

To conclude, the paper confirmed the positive and significant effect of local university research activities on regional innovative activities. However, in addition to this finding, which was already highlighted by the previous literature, this study also revealed that the effect of local research efforts might be overestimated if we do not take into account the spatial extent of knowledge spillovers. Therefore, our study showed that in addition to intraregional knowledge spillovers, there exist also inter-regional industrial and academic knowledge spillovers across German lands which increase regional innovative activities in this country. This finding implies that innovation policy in Germany should focus on supporting both industrial as well as university research. Moreover, innovation policy is expected to create externalities: supporting industrial and university research in a given German land will contribute to knowledge production in the neighbouring regions.

Appendix. The list of German states used in the empirical study:

Baden-Wurttemberg,

Bavaria,

Berlin,

Brandenburg,

Bremen,

Hamburg,

Hesse,

Lower Saxony,

Mecklenburg-Vorpommern,

North Rhine-Westphalia,

Rhineland-Palatinate,

Saarland,

Saxony,

Saxony-Anhalt,

Schleswig-Holstein,

Thuringia.

\section{References}

Acs, Z, Audretsch, D \& Feldman, M 1994, 'R\&D spillovers and recipient firm size', Review of Economics and Statistics, vol. 76, no. 2, pp. 336-340.

Anselin, L, Varga, A \& Acs, Z 1997, 'Local geographic spillovers between university research and high technology innovations', Journal of Urban Economics, vol. 42, no. 3, pp. 422-448.

Anselin, L, Varga, A \& Acs, Z 2000, 'Geographic and sectoral characteristics of academic knowledge externalities', Papers in Regional Science, vol. 79, no. 4, pp. 435-443.

Audretsch, DB \& Feldman, MP 1996, 'R\&D spillovers and the geography of innovation and production', American Economic Review, vol. 86, no. 3, pp. 630-640.

Audretsch, DB, Lehmann, EE \& Warning, S 2005, 'University spillovers and new firm location', Research Policy, vol. 34, no. 7, pp. 1113-1122.

Audretsch, DB, Hulsbeck, M \& Lehmann, E 2012, 'Regional competitiveness, university spillovers, and entrepreneurial activity', Small Business Economics, vol. 39, no. 3, pp. 587-601.

Castellani, D, Jimenez, A \& Zanfei, A 2013, 'How remote are R\&D labs? Distance factors and international innovative activities', Journal of International Business Studies, vol. 44, no. 7, pp. 649-675.

Fischer, M \& Varga, A 2003, 'Spatial knowledge spillovers and university research: Evidence from Austria', Annals of Regional Science, vol. 37, no. 2, pp. 303-322.

Fritsch, M \& Franke, G 2004, 'Innovation, regional knowledge spillovers and R\&D cooperation', Research Policy, vol. 33, no. 2, pp. 245-255.

Funke, M \& Niebuhr, A2000, 'Spatial R\&D spillovers and economic growth: evidence from West Germany', Hamburgisches Welt-Wirtschafts-Archiv Discussion Paper, no. 98.

Gaspar, J \& Glaeser, E 1996, 'Information technology and the future of cities", NBER Working Paper, no. 5562.

Griliches, Z 1979, 'Issues in assessing the contribution of research \& development to productivity growth', Bell Journal of Economics, vol. 10, no. 1, pp. 92-116.

Harris, CD 1954, 'The market as a factor in the localization of industry in the United States', Annals of the Association of American Geographers, vol. 44, no. 4, pp. 315-348.

Jaffe, AB 1989, 'Real effects of academic research', American Economic Review, vol. 79, no. 5, pp. 957-970.

Jaffe, AB, Trajtenberg, M \& Henderson, R 1993, 'Geographic localization of knowledge spillovers as evidenced by patent citations', Quarterly Journal of Economics, vol. 108, no. 3, pp. 577-598.

Link, AN \& Rees, J 1990, Firm size, university based research, and the returns to R\&D, Small Business Economics, vol. 2, no. 1, pp. 25-31.

Nelson, RR 1986, 'Institutions supporting technical advance in industry', American Economic Review, vol. 76, no. 2, pp. 186-189.

Varga, A 2000, 'Local academic knowledge transfers and concentration of economic activities', Journal of Regional Science, vol. 40, no. 2, pp. 289-309. 